\title{
Оригенисты и оригенизм IV-VI вв. в истории и историографии
}

\author{
Стржалковская А.Д., Фуникова С.В. \\ Белгородский государственный национальный исследовательский университет, \\ Росиия, 308015, г. Белгород, ул. Победы, 85, \\ E-mail: Strzhalkovskaya@bsu.edu.ru; funikova@bsu.edu.ru
}

\begin{abstract}
Аннотация. Данная статья посвящена исследованию некоторых представителей оригенизма, встречающихся в источниках. К самым известным личностям такого рода относятся Домициан Анкирский и Феодор Аскида. Оба они были назначены на выдающиеся епископские кафедры: Домициан - на Анкирскую, а Феодор Аскида - на Кесарие-Каппадокийскую. Ещё есть два имени оригенистов, известных исследователям, - это одаренный мистическим восторженным красноречием Нонн и его постоянный спутник Леонтий Византиец. Именно Нонн увлек в ересь Домициана и Феодора Аскиду. Следующий представитель этой группы - Александр Абильский, возглавивший сопротивление иноков Новой Лавры. У Цезаря Барония мы встречаем упоминание еще одного имени оригениста - это некий Руфин. С оригенизмом также в определенной степени связано имя Евагрия Понтийского.
\end{abstract}

Ключевые слова. Оригенизм, оригенисты, представители, осуждение, богословские споры.

Для цитирования: Стржалковская А.Д., Фуникова С.В. 2021. Оригенисты и оригенизм IV-VI вв. в истории и историографии. Via in tempore. История. Политология, 48 (2): 284-289. DOI: $10.52575 / 2687-0967-2021-48-2-284-289$.

\section{Origenists and origenism in 4 th-6th cent. A. D. in history and historiography}

\author{
Anastasia D. Strzhalkovskaya, Svetlana V. Funikova \\ Belgorod National Research University, \\ 85 Pobeda St., Belgorod, 308015, Russia \\ E-mail: Strzhalkovskaya@bsu.edu.ru; funikova@bsu.edu.ru
}

\begin{abstract}
This article is devoted to the study of some personalities who are called Origenists in sources and among researchers. The most famous personalities include Domitian of Ankyrsky and Theodore Askis. Both of them were appointed to prominent episcopal sees: Domitian - to Ancyra, and Theodore Askis - to Caesarea-Cappadocia. There are also two names of Origenists known to researchers - this is Nonn, gifted with mystical enthusiastic eloquence, and his constant friend Leonty Byzantium. It was Nonn who carried Asceis into the heresy of Domitian and Theodore. The next representative of this diaspora is Alexander Abilsky, who led the resistance of the monks of the New Lavra. In Caesar Baronius we find mention of another name of the Origenist - a certain Rufinus. The name Evagrius of Pontus is also associated with Origenism. Origenism before its condemnation in the middle of the 6th century. posed a serious threat to orthodoxy. Origenism is sometimes called «intellectual heresy» in the context of the connection of some of the ideas of Origenism with ancient philosophy.
\end{abstract}

Keywords: Origenism, origenists, representatives, condemnation, theological controversy.

For citation: Strzhalkovskaya A.D., Funikova S.V. 2021. Origenists and origenism in 4th-6th cent. A. D. In history and historiography. Via in tempore. History and political science, 48 (2): 284-289 (in Russian). DOI: $10.52575 / 2687-0967-2021-48-2-284-289$. 


\section{Введение}

В ортодоксальных источниках византийского времени, как и в целом в ортодоксальной традиции, оригенистов принято называть еретиками [Иванцов-Платонов, 1877; Иванов, Цыпин, 2006; Иванов, 2008]. Название «оригенизм» появилось еще в Древней Церкви и встречается в источниках, например у Епифания Кипрского в «Панарионе»: «Некоторые еретики называются оригенистами. Этот род ереси находится не везде» [Епифаний, 1872, с. 73]. Также и у Иоанна Дамаскина в книге «О ста ересях вкратце» весьма нелестно описывается оригенизм: «Оригенисты: от некоего Оригена. Это - бесстыдники, делающие то, о чем и говорить не позволительно, и предающие свои тела растлению» [Иоанн Дамаскин, 1913, с. 133].

Точное место появления самих оригенистов неясно. Наименования «оригенизм» и «оригенисты» произошли от имени Оригена, крупного богослова и учителя Церкви (185-254 гг.), труды которого, как известно, были осуждены на V Вселенском Соборе 533 г.; некоторые не согласные с этим осуждением остались верны утверждениям Оригена, они и вошли в историю как оригенисты.

На данный момент перед нами стоит задача - дать характеристику некоторым приверженцам оригенизма как историческим деятелям и определить их роль и место в церковной истории.

\section{Результаты и их обсуждение}

Прежде чем приступить к описанию жизни и взглядов самых видных деятелей оригенизма, отметим, что его наиболее часто связывают с идейными течениями в богословии VI в., а территориально локализуют преимущественно в монашеских общинах в Палестине. Как известно, в Палестине того времени существовала «цитадель оригенистов» Новая Лавра. С 547 г. приверженцы наиболее крайнего направления оригенизма из Новой лавры получили наименование «исохристы» [Карташев, 2002].

Наиболее ранний автор, который связывается с оригенизмом, - Евагрий Понтийский. Он жил в IV веке и был монахом в Келлийской пустыне в Египте. С оригенизмом его связывают по причине того, что он высказывал некоторые еретические идеи, подобные учению Оригена, за что и был осуждён на V Вселенском Соборе (553 г.) вместе с Оригеном как еретик. Его осуждение было подтверждено VI Вселенским собором.

Самыми известными по количеству упоминаний в источниках оригенистами стали Домициан Анкирский и Феодор Аскида. О них же говорят и практически все исследователи, касавшиеся оригенистской проблематики в историографии.

У А.В. Карташева мы находим эти имена, где они описаны как палестинские монахи-оригенисты, присутствовавшие на соборе Константинопольского патриарха Мины в 536 г. Оба они в столице проявили свою богословскую интеллигентность и были назначены на выдающиеся епископские кафедры: Домициан - на Анкирскую, а Феодор Аскида на Кесарие-Каппадокийскую. Как полезные помощники по церковному управлению, оба они даже не были посланы на свои места, а остались в столице. Особым доверием у самого императора Юстиниана пользовался Феодор Аскида [Карташев, 2002].

Также эти два имени называет Альфонс Курэ, утверждая то, что эти люди явно были оригенистами: «То были Домициан, настоятель монастыря Мартирия, и Феодор Аскида, экзарх Новой Лавры. Оба они за услуги, оказанные ими православию, были призваны на епископские престолы» [Курэ, 1894, с. 110]. Домициан стал епископом Анкиры, а Феодор - Кесарии Каппадокийской. Эти личности не просто благосклонно относились к учению Оригена, а являлись его страстными приверженцами, так как были выходцами из Новой Лавры [Курэ, 1894, с. 110]. Вероятно, именно по той причине в этот период Каппадокия с главными городами Кесарея, Колония, Севастия и её пещерные монастыри стали убежищем огромного количества изгнанников, не желавших и не согласных отречься от своей веры [Брокгауз, 2012]. 
Более подробно остановимся на Феодоре Аскиде (оригенист-епископ Кесарии Каппадокийской), деятельность которого подробно анализируется в монографии М.В. Грацианского. Особо отмечено то, что, находившись в Константинополе из-за некоторых предложенных новых мер против «антиохийской» христологии, он начал наводить идейную смуту в придворных кругах. Некоторые его идеи очень понравились Юстиниану, который думал, как достойно ответить на обвинения монофизитов в том, что Халкидон реабилитировал «друзей Нестория» Иву Эдесского и бл. Феодорита Киррского. Таким образом, оригенистские круги оказались несколько искусственно объединенными с проблемой «Трех глав». Далее М.В. Грацианский не соглашается с данной позицией: «Во-первых, спор о Трёх Главах лишь с трудом можно поставить в прямую связь с оригенистским спором, в котором активную роль играл Аскида. Поэтому является неясным, как пресловутый оригенизм Аскиды мог навести его на мысль выступить против Трёх Глав или же настроить против них императора. Во-вторых, анафема Трём Главам на Пятом Вселенском Соборе сопровождалась анафемой учению Оригена, что дополнительно указывает на то, что оригенист Феодор Аскида не мог стоять за этим решением» [Грацианский, 2007, с. 7-26]. Напротив же, Альфонс Курэ имеет иное мнение и считает, что оригенисты при дворе Юстиниана оказали влияние на спор о Трёх Главах [Курэ, 1894, с. 112].

Эту спорную проблему удачно разрешает, на наш взгляд, М.В. Грацианский, утверждая, что идея о том, что именно оригенисты злонамеренно вызвали спор о Трёх Главах, была достаточно широко распространена в православных кругах. Так, её сторонником был, например, Факунд Гермианский [Грацианский, 2007, с. 7-26]. Но оригенисты из злого умысла нападали на Три Главы, поскольку тем самым они хотели отомстить антиоригенистам. Поскольку Юстиниан сам издал антиоригенистские эдикты, эта месть была направлена, судя по всему, на него. Почему для этой мести оригенисты выбрали именно Три Главы, непонятно. Факунд утверждает, что тем самым они хотели отменить Халкидонский Собор, что само по себе сомнительно ввиду того, что оригенисты никоим образом не были антихалкидонитами. Далее, если предположить, что они открыто заявили о своих намерениях (как Домициан в письме к Вигилию), то придётся смириться с тем фактом, что оригенисты хотели принудить Юстиниана служить своим тёмным целям. Получается, что этим целям наивный Юстиниан был вынужден со рвением служить в течение 16 лет! С такой трактовкой абсолютно невозможно согласиться [Грацианский, 2016, с. 184-186]. И далее М.В. Грацианский приводит аргумент в защиту своего мнения: нельзя не учесть, что деятельность Феодора Аскиды против Трёх Глав началась уже после появления императорского эдикта против оригенистов в конце 542 или начале 543 г. В свете этих аргументов тезис о том, что Феодор Аскида стал зачинщиком спора о Трёх Главах, представляется не выдерживающим критики. Инициатива их осуждения принадлежала, как всегда, Юстиниану [Грацианский, 2007, с. 7-26; Геростергиос, 2010].

Также высказывались мнения о том, что поскольку различные политические силы того времени были весьма заинтересованы в осуждении Трех Глав, то приходится считать данную меру императора интригой, в которой его в своих целях использовал Феодор Аскида. М.В. Грацианский дает этому мнению следующую отповедь: «Во-первых, спор о Трех Главах лишь с трудом можно поставить в прямую связь с оригенистским спором, в котором активную роль играл Аскида. Идея, что именно оригенисты злонамеренно вызвали спор о Трех Главах, была достаточно широко распространена в православных кругах. Так, ее сторонником был, например, Факунд Гермианский. Но как пресловутый оригенизм Аскиды мог навести его на мысль выступить против Трех Глав или же настроить против них императора, в конечном итоге остается неясным» [Грацианский, 2016, с. 220].

Мы знаем о друге Феодора, упоминаемом вместе с ним, это оригенист Домициан (VI в.), епископ Анкирский. Он был палестинским монахом, игуменом лавры Фирмина, которая, как и Новая Лавра, в какой-то момент была оплотом оригенизма. В 536 г. он прибыл в Константинополь, где участвовал в Константинопольском Соборе. Как сообщают источники, он имел знакомство через Леонтия Византийского с пресвитером Евсевием, советником императора Юстиниана I, и именно он помог ему предстать перед императо- 
ром. В 540 г. Юстиниан, благоволивший Домициану, сделал его епископом Анкиры (Галатия). Как известно, Домициан Анкирский был близким другом Феодора Аскиды, одного из главных проводников императорской политики времени спора о Трех Главах (539-553 гг.). Вместе с ним Домициан ходатайствовал перед императором за патриарха Петра Иерусалимского, разорвавшего общение с патриархом Ефремом Антиохийским, когда тот первым осудил оригенизм (542 г.) [Грацианский, 2012; Kyrillos, 1939].

Ещё встречаются два имени оригенистов - это описываемый как одаренный мистическим восторженным красноречием Нонн и его постоянный товарищ Леонтий Византиец. Их несколько раз изгоняли настоятели монастыря Новой Лавры, так как настоятели не принадлежали к приверженцам учения Оригена и часто назначались св. Саввой Освященным из великой Лавры, хотя один из настоятелей - Мамма - принял иноков и их мистические рассуждения [Курэ, 1894, с. 112].

Леонтий Византиец, находясь в Константинополе, вошел в доверие к епископу Кизикскому и потом, находясь в хорошем положении в столице, ввел туда Домициана и Феодора Аскиду. Говоря о Леонтии Византийском, исследователи четко пишут, что он был писатель и оригенист [Леонтий, 2006, с. 15]. Мы имеем в виду Леонтия-оригениста, жившего в VI веке в период правления Юстиниана Великого. При жизни Леонтий Византийский принял монашеский постриг и стал насельником Новой Лавры в Палестине. Леонтий не оставил после себя при жизни никаких литературных трудов [Леонтий, 2006, с. 53]. Здесь не стоит путать этого Леонтия с Леонтием-писателем, жившим в VII в. и оставившим после себя большое литературное наследие [Леонтий, 2006, с. 54].

В некоторых источниках также встречается имя еще одного оригениста - Нонн. По мнению Курэ, именно этот Нонн увлек в ересь Домициана и Феодора Аскиду [Курэ, 1894, c. 112]. Нонн осуществлял свою деятельность в Палестинских монастырях, а впоследствии авва Нонн стал предводителем оригенистов в Новой Лавре, вступившим в противостояние с самим Саввой Освященным. По известным нам сведениям, из-за этих волнений Савва посетил императора Юстиниана в 531 г. и просил содействия в борьбе с Нонном и его сторонниками. Каких-либо более подробных сведений о Нонне нами не найдено. Вероятно, его личность требует более подробного изучения и поиска биографических сведений о нем в источниках.

Следующее имя мы встречаем только в одном месте это - Александр Абильский. Он возглавил движение иноков Новой Лавры. Затем был изгнан патриархом иерусалимским Евстохием. Александр Абильский создал фактически «государство в государстве» [Курэ, 1894, с. 116].

У Цезаря Барония мы встречаем упоминание еще одного имени оригениста - это некий Руфин: «Анастасий, папа, Руфина оного оригениста к себе призвал, дабы отвечал в заблуждениях Оригеновых» [Бароний, 1914, с. 415].

Таковы лишь некоторые представители оригенизма ранневизантийского времени [Кулаковский, 2003], и о каждом из них необходимо продолжить исследования, а в дальнейшем расширить и дополнить этот список. Причиной скудной информации по данной теме, вероятно, стали попытки уничтожить сведения о ересях и представителях этих направлений [Вальденберг, 2008].

\section{Заключение}

Заключить наш обзор можно словами Епифания Кипрского (315-403 гг.) об оригенистах, высказанными, когда эта ересь только начиналась: «Отразив и эту ересь как бы страшную змею, именуемую ехидною, которая ростом мала, но испускает ужасное по своей ядовитости дыхание и наносит гибель приближающимся к ней, - сокрушив ее, перейдем к следующим ересям, призвав Бога на помощь к совершению всего труда нашего в Боге» [Епифаний, 1872, с. 79]. Отсюда видим, что церковные авторы нелестно отзывались об оригенистах, а некоторые вообще предпочитали не упоминать их имена и замалчивали биографии. Вероятно, по причине такого негативного отношения к этим личностям о них 
сохранились лишь обрывочные сведения в источниках [Иванова, 2006]. От этого интерес к оригенистам ныне только возрастает [Таевский, 2003].

\section{Список литературы}

1. Бароний Ц. 1914. Деяния церковные и гражданские от рождества Христова до 1198 лета. Москва, Типография Т-ва Рябушинских, 967.

2. Брокгауз Ф.А., Ефрон А.И. 2012. Энциклопедический словарь Брокгауз и Ефрон. http://www.vehi.net/brokgauz/all/106/106461.shtml.

3. Вальденберг В.Е. 2008. История византийской политической литературы в связи с историей философских течений и законодательства. Санкт-Петербург, Дмитрий Буланин, 412.

4. Геростергиос А. 2010. Юстиниан Великий - император и святой. Москва, Изд-во Сретенского монастыря, 448.

5. Грацианский М.В. 2012. Дометиан. Православная энциклопедия. Т. 15: 603-604.

6. Грацианский М.В. 2016. Император Юстиниан Великий и наследие Халкидонского Собора. Москва, Изд-во Московского университета, 391.

7. Грацианский М.В. 2007. Св. император Юстиниан и спор о Трёх Главах (540-553 гг.). Вестник Православного Свято-Тихоновского гуманитарного университета. Серия 1: Богословие. Философия. Религиоведение. Т. 17, 1: 7-26.

8. Епифаний Кипрский. 1872. Творения, часть 3. Москва, Типография Готье на Кузнецком мосту, 458.

9. Иванов М.С. 2008. Еретик. Православная энциклопедия Т. 18: 607-610.

10. Иванов М.С., Цыпин В. 2008. Ересь. Православная энциклопедия. Т. 18: 598-607.

11. Иванова И.И. Рационалистические ереси в истории христианства. 2006. Москва, Дисс. д. и. н. спец. 09.00.13, 351.

12. Иванцов-Платонов А.М. 1877. Ереси и расколы первых трёх веков христианства. Москва. Кн. 1, 348.

13. Иоанн Дамаскин. 1913. Полное собрание творений. О ересях вкратце. СанктПетербург, Изд-во Санкт-Петербургской Духовной Академии, 441.

14. Карташев А.В. 2002. Вселенские соборы. Клин, Христианская жизнь, 512.

15. Кулаковский Ю.А. 2003. История Византии. В 3-х томах. 3-е изд. Санкт-Петербург, Алетейя, 476.

16. Курэ А. 1894. Палестина под властью христианских императоров. Санкт Петербург, Русский паломник, 635.

17. Леонтий Византийский: сборник исследований. 2006. Москва, Империум пресс, Центр библейско-патрологических исследований, 671.

18. Таевский Д.А. 2003. Христианские ереси и секты I-XXI веков. Москва, Интрада, 320.

19. Kyrillos von Skythopolis. 1939. Werke. Lpz., Teubner, 510.

20. Jones A.H.M. 1964. The Later Roman Empire 284-602. Vol.2. Oxford, Basil Blackwell, VI, 545.

\section{Referenses}

1. Baronij C. 1914. Dejanija cerkovnye i grazhdanskie ot rozhdestva Hristova do 1198 leta [Church and civil acts from the birth of Christ to 1198 years]. Moskva, Tipografija T-va Rjabushinskih, 967 (in Russian).

2. Brokgauz F.A., Efron A.I. 2012. Jenciklopedicheskij slovar' Brokgauz i Efron [Encyclopedic Dictionary Brockhaus and Euphron]. URL: http://www.vehi.net/brokgauz/all/106/106461.shtml (in Russian).

3. Val'denberg V.E. 2008. Istorija vizantijskoj politicheskoj literatury $\mathrm{v}$ svjazi $\mathrm{s}$ istoriej filosofskih techenij i zakonodatel'stva [History of Byzantine political literature in connection with the history of philosophical trends and legislation]. Sankt-Peterburg, Dmitrij Bulanin, 412 (in Russian).

4. Gerostergios A. 2010. Justinian Velikij - imperator i svjatoj [Justinian the Great - Emperor and Saint]. Moskva, Izd-vo Sretenskogo monastyrja, 448 (in Russian).

5. Gracianskij M.V. 2012. Dometian [Dometian]. In: Pravoslavnaja jenciklopedija [Orthodox encyclopedia]. T. 15: 603-604 (in Russian).

6. Gracianskij M.V. 2016. Imperator Justinian Velikij i nasledie Halkidonskogo Sobora [Emperor Justinian the Great and the legacy of the Council of Chalcedon]. Moskva, Izd-vo Moskovskogo universiteta, 391 (in Russian). 
7. Gracianskij M.V. 2007. Sv. imperator Justinian i spor o Trjoh Glavah (540-553 gg.) [Holy Emperor Justinian and the dispute about the Three Chapters (540-553)]. In: Vestnik Pravoslavnogo Svjato-Tihonovskogo gumanitarnogo universiteta. Serija 1: Bogoslovie. Filosofija. Religiovedenie [Bulletin of the Orthodox St. Tikhon University for the Humanities. Series 1: Theology. Philosophy. Religious studies]. T. 17, 1: 7-26 (in Russian).

8. Epifanij Kiprskij. 1872. Tvorenija [Creations], chast' 3 [part 3]. Moskva, Tipografija Got'e na Kuzneckom mostu, 458 (in Russian).

9. Ivanov M.S. 2008. Eretik [Heretic]. In: Pravoslavnaja jenciklopedija [Orthodox encyclopedia]. T. 18: 607-610 (in Russian).

10. Ivanov M.S., Cypin V. 2008. Eres' [Heresy]. In: Pravoslavnaja jenciklopedija [Orthodox encyclopedia]. T. 18: 598-607 (in Russian).

11. Ivanova I.I. 2006. Racionalisticheskie eresi v istorii hristianstva [Rationalistic heresies in the history of Christianity]. Moskva, Diss. d. i. n. spec. 09.00.13, 351 (in Russian).

12. Ivancov-Platonov A.M. 1877. Eresi i raskoly pervyh trjoh vekov hristianstva [Heresies and schisms of the first three centuries of Christianity]. Moskva. Kn. 1, 348 (in Russian).

13. Ioann Damaskin. 1913. Polnoe sobranie tvorenij. O eresjah vkratce [Complete collection of creations. Briefly about heresies]. Sankt-Peterburg, Izd-vo Sankt-Peterburgskoj Duhovnoj Akademii, 441 (in Russian).

14. Kartashev A.V. 2002. Vselenskie sobory [Ecumenical Councils]. Klin, Hristianskaja zhizn', 512 (in Russian).

15. Kulakovskij Ju.A. 2003. Istorija Vizantii [History of Byzantium]. V 3-h tomah. 3-e izd. Sankt-Peterburg, Aletejja, 476 (in Russian).

16. Kure A. 1894. Palestina pod vlast'ju hristianskih imperatorov [Palestine under the rule of Christian emperors]. Sankt Peterburg, Russkij palomnik, 635 (in Russian).

17. Leontij Vizantijskij: sbornik issledovanij [Leonty Byzantine: collection of studies]. 2006. Moskva, Imperium press, Centr biblejsko-patrologicheskih issledovanij, 671 (in Russian).

18. Taevskij D.A. 2003. Hristianskie eresi i sekty I-XXI vekov [Christian heresies and sects of the I-XXI centuries]. Moskva, Intrada. 320.

19. Kyrillos von Skythopolis. 1939. Werke. Lpz., Teubner, 510.

20. Jones A.H.M. 1964. The Later Roman Empire 284-602. Vol.2. Oxford, Basil Blackwell, VI, 545.

\section{ИНФОРМАЦИЯ ОБ АВТОРАХ}

Стржалковская Анастасия Дмитриевна, кандидат исторических наук, старший преподаватель кафедры русского языка, профессионально-речевой и межкультурной коммуникации Белгородского государственного национального университета, г. Белгород, Россия

Фуникова Светлана Владимировна, кандидат филологических наук, доцент кафедры русского языка, профессионально-речевой и межкультурной коммуникации Белгородского государственного национального исследовательского университета, г. Белгород, Россия

\section{INFORMATION ABOUT THE AUTHORS}

Anastasia D. Strzhalkovskaya, candidate of Historical Sciences, Senior Lecturer of the Department of Russian Language, Professional Speech and Intercultural Communication, Belgorod State National Research University, Belgorod, Russia

Svetlana V. Funikova, candidate of Philology, Associate Professor of the Department of Russian Language, Professional Speech and Intercultural Communication, Belgorod State National Research University, Belgorod, Russia 